\title{
Geospatial View of Air Pollution and Health Risk over North Indian Region in COVID-19 Scenario
}

Dharmendra Singh ( $\nabla$ dharmbaghel01@gmail.com )

Haryana Space Applications Centre https://orcid.org/0000-0001-8528-8637

\section{Minakshi Dahiya}

Haryana Space Applications Centre

Chintan Nanda

Haryana Space Applications Centre

\section{Research Article}

Keywords: COVID-19, Air Quality, Excess Health Risk, North India, Criteria Pollutants

Posted Date: November 30th, 2020

DOI: https://doi.org/10.21203/rs.3.rs-115247/v1

License: (c) (i) This work is licensed under a Creative Commons Attribution 4.0 International License.

Read Full License

Version of Record: A version of this preprint was published at Journal of the Indian Society of Remote Sensing on February 24th, 2022. See the published version at https://doi.org/10.1007/s12524-022-01520-

Z. 


\section{Abstract}

Air pollutant concentration, Air Quality Index (AQI) and Excess Risk (ER \%) is assessed in three scenarios including pre-lockdown, lockdown and post-lockdown based on 47 ground station data (during January 2020 to June 2020) distributed over northern part of India using statistics and geographic information system (GIS) techniques. Significant decrease in pollutants concentration, AQI and ER \% was observed in lockdown period amid COVID-19. $\mathrm{PM}_{2.5}, \mathrm{PM}_{10}, \mathrm{NO}_{2}, \mathrm{NH}_{3}$ and $\mathrm{CO}$ decreased by $46 \%, 31 \%, 39 \%, 24 \%$ and $34 \%$ respectively, in lockdown scenario as compared to the pre-lockdown scenario. A decrease of $39 \%$ in $\mathrm{AQI}$ was observed as compared to pre-lockdown scenario however the difference was less when compared with post-lockdown scenario. The decrease in total ER \% was $60.36 \%$ over the study area due to improvement in air quality amid COVID-19 lockdown. The meteorological conditions were found consistent in the current year with respect to previous year and very less influence was observed on the concentration of air pollutants. The major implications of the current findings are air pollution management, health risk management, and pollution source and type identification.

\section{Introduction}

In these days world population is facing threat from the Corona Virus which is also known as COVID-19. Corona Virus causes respiratory illness such as severe acute respiratory syndrome [1]. This has modified the anthropogenic activities across the world in terms of reduced human movement, reduced vehicle emissions and reduction in industrial activities which showed reduced level (ranging from 10 to $50 \%$ ) of air pollution/pollutants across the Globe $[2,3,4,5,6,7]$. In China human activity reduced by $69.85 \%$ in 44 cities and because of that Air Quality Index (AQI), Particulate Matter 2.5 ( $\left.\mathrm{PM}_{2.5}\right)$, Carbon Monoxide (CO) were partially mediated and Particulate Matter 10, Sulphur dioxide (SO2) and Nitrogen dioxide (NO2) completely mediated [8]. In lockdown, transport, social activities and consumption of oil has been attenuated distinctly $[3,9]$.

First person affected by corona virus was found in the Wuhan city of the China [10]. As on 12 August 2020 , total positive cases of coronavirus was $20,120,919$ and with 736,766 deaths all over the world [11]. In Indian, the first COVID-19 patient was detected in the Kerala state on $30^{\text {th }}$ January 2020 who returned from Wuhan, China. As of 20 October, 2020 India is having 7,48,538 active patients and 1,15,197 death along with 67,33,328 discharged survivors with unknown future risks (https://www.mohfw.gov.in/).

India is the $2^{\text {nd }}$ largest populated country after China with high population density, poor infrastructure along with meagre health care facilities, has high risk from pandemic COVID-19. When affected patients were increased day by day, Indian government takes action to control the spread of COVID-19 in India and declared first lockdown for 21 days in the country on 24 March 2020 after a complete curfew on 22 March, 2020. Non-essential services like school, colleges, markets, shopping mall, offices \& tourist place were banned completely while essential services (water, electricity department, bank, hospitals, pharmaceutical store, milk dairy etc.) were allowed during lockdown [12]. 
Air is the most important natural resources for entire living world. Air with its quality affects both biotic and a-biotic components of the earth environment and gets affected by them also. Global data indicates that $90 \%$ people breathe polluted air which creates health risk to millions of earth habitants. In 2015 one million people were died due to excessive concentration of ambient particulate matter (PM) [13]. Air pollution is the major threat for the Indian people, as it has 21 worlds most polluted cities in the list of world's 30 . Further, the northern part of the country faces high pollution level and poor air quality $[14,15]$.

The air quality of a region is decided based on the concentration of air pollutants such as PM2.5, PM10, SO2, NOx, $\mathrm{CO}$ and $\mathrm{O} 3$ among others. Major sources of the air pollutant are biomass burning, industrial activities and vehicular emissions and all these are governed by anthropogenic activities. Thus, changes in the pattern and magnitude of anthropogenic activities have clear impact on air quality $[16,17,18,19]$. After lockdown, amid COVID-19, people feel significant changes in air quality all across the globe and this was only due to reduced anthropogenic activities $[20,2,5,6,21]$. However, some researchers have also focused on meteorological control on pollution during lockdown [22].

Meteorological parameters also influences the concentration of air pollutants in the atmosphere $[23,24,25]$. Researchers found the influence of temperature on the concentration of SO2 and NO2. High influence is found in summer season and low in other season. No significant relationship was obtained between relative humidity $(\mathrm{RH})$ and SO2/NO2 and while it was found to be negatively correlated with PM [24]. Concentration of pollutants were found to be positively correlated with temperature and negatively correlated with wind speed and relative humidity [25]. However, [26] reported that the pollutant concentration was low when the temperature or wind speed was high. It was found that the metrological parameters have small change in the year 2020 when compared with previous year's data but a huge change was observed in the concentration of pollutants. It was also observed that the meteorology has not influenced to air quality during lockdown period [27]. However, it is primarily important to conform the influence of meteorological parameters on pollutant concentration during our study period so that it could be strongly concluded that changes in pollutant concentration is due to COVID-19 driven lockdown.

Lots of research has been done on the effect of lockdown on air quality in India based on ground data and satellite data $[4,5,6,21,28,29]$. In Lucknow and New Delhi major impacts of lockdown were observed on the concentration of PM2.5, NO2 and CO and less on the SO2 [6]. In Delhi and Mumbai NO2 concentration get declined by $40-50 \%$ due to Lockdown [30]. When the data of air pollutant of the year 2018, $2019 \& 2020$ were compared for various cities of India, researchers found decrease in the concentration of PM2.5, PM10 \& Ozone (03) as compared to the last two years but there were no change in the temperature and humidity [20].

Above mentioned works have only focused either on individual air pollutants or AQI variability due to COVID-19 driven lockdown, using ground or satellite data. Very few studies have focused a complete scenario starting from individual pollutant level to AQI to further health risk or Excess Risk (ER \%) due to COVID-19 driven lockdown. Further spatial studies related to ER \% over the currently taken region (part of Indo-Gangetic plain) is lacking in spite its urgent need. [5] reported 4 times reduction in total ER \% due to 
COVID-19 lockdown over various parts of India however, the spatial distribution of AQI, and ER \% were not attempted.

Thus the current study is being done to analyse the variability in air pollutants, AQI and ER \% in three scenarios viz. Pre-Lockdown (1 January 2020 to 21-March, 2020), During Lockdown (22 March 2020 to 31 may 20202) \& Post Lockdown (1 June 2020 to 30 June 2020) using ground based data and GIS technologies. The key objectives of the study are to (a) assess the impact of COVID-19 driven lockdown on air pollutants (b) assess the variations in AQI and ER \% in response to COVID-19 driven lockdown (c) influence of meteorological parameters on individual pollutants, AQI and ER\%.

\section{Results}

\section{Impact of COVID-19 driven lockdown on the Concentration of in-situ Criteria Pollutants}

Individual pollutant concentrations showed high values during pre-lockdown, minimum values during lockdown and low values during post-lockdown (supplementary material figure S2 to S8). The spatial variations for $\mathrm{PM} 2.5 \mathrm{PM} 10, \mathrm{NO} 2, \mathrm{NH} 3, \mathrm{CO}, \mathrm{O} 3$ and $\mathrm{SO} 2$ in three lockdown scenarios are presented in supplementary materials as Figure S2 to S8 respectively. Mean and SD of criteria pollutants viz. PM2.5, PM10, NO2, NH3, CO, 03 and SO2 were $71 \pm 45 \mu \mathrm{g} / \mathrm{m}^{3}, 139 \pm 72 \mu \mathrm{g} / \mathrm{m}^{3}, 28 \pm 21 \mu \mathrm{g} / \mathrm{m}^{3}, 33 \pm 24 \mu \mathrm{g} / \mathrm{m}^{3}$, $1.00 \pm 0.65 \mathrm{mg} / \mathrm{m}^{3}, 29 \pm 20 \mu \mathrm{g} / \mathrm{m}^{3}$ and $13.8 \pm 11 \mu \mathrm{g} / \mathrm{m}^{3}$ in pre-lockdown, $39 \pm 20 \mu \mathrm{g} / \mathrm{m}^{3}, 96 \pm 55 \mu \mathrm{g} / \mathrm{m}^{3}, 17 \pm 13$ $\mu \mathrm{g} / \mathrm{m}^{3}, 25 \pm 18 \mu \mathrm{g} / \mathrm{m}^{3}, 0.7 \pm 0.5 \mathrm{mg} / \mathrm{m}^{3}, 39 \pm 23 \mu \mathrm{g} / \mathrm{m}^{3}$ and $13.7 \pm 11.6 \mu \mathrm{g} / \mathrm{m}^{3}$ were during lockdown and $40 \pm 17 \mu \mathrm{g} / \mathrm{m}^{3}, 105 \pm 57 \mu \mathrm{g} / \mathrm{m}^{3}, 18 \pm 12 \mu \mathrm{g} / \mathrm{m}^{3}, 29 \pm 22 \mu \mathrm{g} / \mathrm{m}^{3}, 0.7 \pm 0.6 \mathrm{mg} / \mathrm{m}^{3}, 39 \pm 22 \mu \mathrm{g} / \mathrm{m}^{3}$ and $12.7 \pm 8.9$ $\mu \mathrm{g} / \mathrm{m}^{3}$ were in post-lockdown. Table 2 presents statistical description of criteria pollutants for three scenarios. PM2.5, PM10, NO2, NH3 and CO decreased by $46 \%, 31 \%, 39 \%, 24 \%$ and $34 \%$ in lockdown scenario as compared to the pre-lockdown scenario. Variability of individual air pollutants, AQI and ER\% during the study period (January to June, 2020) is also presented in supplementary material X.

\section{Impact of COVID-19 driven lockdown on Air Quality Index (AQI)}

At the spatial domain, pre-lockdown AQI was high as compared to two other scenarios and six month average AQI (Figure 3 a to d). High mean and SD of AQI (154 \pm 87.58$)$ in pre-lock down scenario was observed. As compared to pre-lockdown, the AQI values $(94 \pm 46.5)$ were significantly less during lockdown, however, in post-lockdown scenario little difference was observed (Table 3 ). The differences are clearly observed in box plot (Figure 3e). A decrease of 39\% in AQI was observed during lockdown from prelockdown scenario. Many activities were started like vehicular movement, industrial activity among others and these were coupled with crop residue burning leads to an increase in AQI values and decrease in air quality of June month (Post-lockdown). 


\section{Excess Risk (ER \%) from Air Pollutants}

Total ER \% is estimated as sum of the ER \% of the five criteria pollutants including PM2.5, PM10, SO2, NO2 \& CO. ER \% was classified into five categories viz. Low (less than 5.64), Moderate (5.64-11.29), High (11.29-12.21), Very High (12.91-19.37) and Serious (greater than 19.37). The ER\% was found to be low during lockdown period. Serious ER\% during pre-lockdown period was observed. Minimum, maximum and mean total ER \% was 10.2, 32.8 and 16.9 in pre-lockdown, 0.69, 16.2 and 6.7 during lockdown and 0.67, 9.7 and 3.3 in post-lockdown respectively. During lockdown total ER\% was less as compared to pre lockdown and average of six months but similar to the post-lockdown (Figure 4 a to d). Whisker plot of $E R \%$ is presented in Figure $4 \mathrm{e}$ and showed similar results. The middle line in the plot represents median and rectangle within the box represents mean value. Significant reduction in ER\% of PM2.5 and PM10 were observed as a result of COVID-19 driven lockdown (Figure S9, supplementary material). Simultaneously, the ER\% from individual pollutant is presented in Figure S10 (supplementary material) showed high contribution of $\mathrm{NO}_{2}$ driven $\mathrm{ER} \%$ indicating the region is affected by vehicular pollution. The same may be observed for total ER\% as represented in Figure S0 (supplementary material).

Statistical analysis of ER\% shows the significant decrease $(\mathrm{p}=0.00)$ during lockdown and post-lockdown when compared with pre-lockdown. This may be because of the increased concentration of PM2.5, SO2 and $\mathrm{NO} 2$. It was observed that the $\mathrm{ER} \%$ is highly affected by $\mathrm{NO}_{2}$ and thus the change in the centration of $\mathrm{NO} 2$ leads to the high ER\% in the last month of May and after lockdown (Supplementary material, Figure S11). At the initial stage of lockdown (24 ${ }^{\text {th }}$ March 2020), all activities including industrial, services and vehicular moment were prohibited (Figure S12 for vehicle movement, supplementary material) which leads to the reduction in pollutants concentration and thus ER\%. But at the end of April, 2020, the lockdown was relaxed which leads to the increase in industrial and vehicular emissions. Stubble burning in north India may have further contributed in the increase of pollutant concentration which leads to the increase in ER\% during post-lockdown scenario.

\section{Effect of Metrological parameters on Air Pollutants AQI and $E R \%$}

In this study inter-correlation among various pollutants and metrological parameters was analysed for the year 2019 and 2020 and found significant correlation among them, but correlation were weak and lies below 0.36 for meteorological parameters and pollutant parameters (Table A5 and Table A6, supplementary material). This showed that the meteorological parameters have less influence on the pollutants concentration. PM2.5 is significantly correlated with relative humidity (RH) in the year 2020 with $r=0.21$ whereas for the year 2019 the correlation was very less. However, from meteorological data analysis it was observed that the $\mathrm{RH}$ for the year 2020 (during lockdown period) is little higher as compared to the $\mathrm{RH}$ of the year 2019 (average difference 9.51\%) but the PM2.5 get reduced significantly (average difference -15.79) (Table A4, supplementary material). This analysis clearly shows that there is very less effect of meteorological data on the concentration of air pollutants (Table A5 and Table A6) and 
thus the anthropogenic activities are responsible for the AQI decrease in the year 2020. It was also observed that the vehicle movement was very less in 2020 (Figure S12, Supplementary material) because of lockdown condition which also confirms that the reduction in AQI values is due to the reduction of anthropogenic activities.

Other air pollutants have significant relation with metrological data such as relative humidity, temperature, wind speed and wind direction with less correlation values (Table A5 and A6, supplementary material). Further, there were no major changes in the temperature of the year 2019 and 2020 as presented in supplementary material Figure S13 and Table A4. Mean value of temperature is $23.87^{\circ} \mathrm{C}$ and $22.27^{\circ} \mathrm{C}$ in 2019 and 2020 respectively. This analysis shows that the AQI is less in 2020 as compared to the AQI in the year 2019 may be because of lockdown condition. RH is little high in the year 2020 as shown in Figure S14 (Supplementary material, Table A4) and AQI is less as compared to the AQI of the year 2019. This shows the reciprocal relationship between AQI and Relative Humidity. Wind speed was $1.8 \mathrm{~m} / \mathrm{s}$ in the year 2019 and $2.27 \mathrm{~m} / \mathrm{s}$ in the year 2020 (supplementary material Figure S15 and Table A4).

\section{Discussion}

This study explains the changes in pollution level, AQI and health risk (ER\%) over northern India during prelockdown, lockdown and post lockdown scenarios amid COVID-19. PM2.5, PM10, NO2, NH3 and CO decreased by $46 \%, 31 \%, 39 \%, 24 \%$ and $34 \%$ during lockdown scenario as compared to the pre-lockdown scenario. SO2 concentration was remained similar during lockdown and pre-lockdown and $\mathrm{O} 3$ concentration was increased during lockdown. The non-variability in $\mathrm{SO} 2$ may be because of unlocked operations of power plant in northern India similar to the previous years. Increased 03 concentration may be due to presence of clear sky condition, sun light and ozone forming nuclei's i.e. NOx and VOCs. The concentration of PM10, PM2.5, NO2, NH3 and $\mathrm{CO}$ shows clear cut reduction due to lockdown as movements of both the vehicle and human was restricted during the lockdown condition (Figure S12, supplementary material) and most of the anthropogenic activities were delimited. Mean value of $\mathrm{CO}$ were remain similar in pre-lockdown and during lockdown condition. However, it increased in post-lockdown period may be because of incomplete biomass burning (Figure S17, supplementary material). Intercorrelation between pollutants showed that the PM2.5 and PM10 are highly correlated with each other $(\mathrm{r} 2=0.6)$ and in agreement with earlier study done by [31]. However, other pollutants were found to be less correlated (Table A5 and A6, supplementary material).

The concentrations of pollutants started increasing in the post-lockdown period i.e. in the month of June (Table 2). Increased concentrations of pollutants in the month of June is due to combined effect of unlock process and crop stubble burning. Overall scenario showed highest concentration of pollutants in the prelockdown, lowest during lockdown and medium after lockdown. Little increase in the level of pollutants in May month is again due to crop stubble burning and allowed anthropogenic activities in relaxed lockdown.

Findings of current study regarding the pollutants level were also compared with reference concentrations reported by other researchers for earlier years in the same region. Current concentrations (i.e. average of last six months) of pollutants (with respect to earlier concentration in bracket) like PM2.5, PM10, NO2, CO, 
O3 and SO2 were $53.39 \mu \mathrm{g} / \mathrm{m}^{3}\left(77 \mu \mathrm{g} / \mathrm{m}^{3}\right.$ in 2019), $117.01 \mu \mathrm{g} / \mathrm{m}^{3}\left(200 \mu \mathrm{g} / \mathrm{m}^{3}\right.$ in 2017-2019) $22.39 \mu \mathrm{g} / \mathrm{m}^{3}$ (31.5 $\mu \mathrm{g} / \mathrm{m}^{3}$ in 2017), $0.82 \mathrm{mg} / \mathrm{m}^{3}$ (1.1 mg/m $\mathrm{m}^{3}$ in 2019), $34.28 \mu \mathrm{g} / \mathrm{m}^{3}\left(44 \mu \mathrm{g} / \mathrm{m}^{3}\right.$ in 2019$), 13.53 \mu \mathrm{g} / \mathrm{m}^{3}$ $\left(15 \mu \mathrm{g} / \mathrm{m}^{3}\right.$ in 2019) $[5,32]$. These values clearly show the reduction in pollutants concentration in 2020 as compared to the earlier years because of lockdown.

AQI during the lockdown period was 94 while in pre-lockdown and post lockdown AQI was 154 and 100 respectively. This reduction in AQI again conform the effect of lockdown amid COVID-19 on air quality improvement. The reduction may be due to varying activities amid COVID-19 lockdown. No activity was allowed during first lockdown while limited activities were allowed in the consecutive lockdown periods. Industrial operations, bus services, personal vehicles, and offices were closed and thus air was observed cleanest during lockdown period with decreased level of air pollutants.

ER \% from the pollutants PM2.5, PM10, SO2, NO2 and CO were also calculated and mean and SD of total ER \% were $16.9 \pm 5.1,3.3 \pm 2.0$ and $6.7 \pm 4.9$ during pre-lockdown, lockdown and post-lockdown respectively. This shows that the ER\% due to air pollution was lowered in lockdown scenario amid COVID-19. Ten out of 47 stations were under the category of high to very high ER \% during the study period. These stations were Muzzaffarnagar, Mahendergarh, Gurugram, Faridabad, Panipat, Delhi, Rohtak, Panchkula, Noida and Fatehgarh Sahib (Table X2, supplementary material). Gurugram, Faridabad and Panipat stations of Haryana were having very high ER\% mainly due to poor air quality resulted from industrial operations, vehicular emissions, stubble burning (Figure S17, supplementary material) and there position near Delhi NCR region. Due to stubble burning ER\% was also high in Panchkula, Rohtak, Mahendargarh. Delhi was also found to be highly polluted and thus very high ER\%. An extended analysis at block level showed that the risk was high in some blocks of Haryana (Faridabad, Hathin, Palwal, Panipat, Ganaur, Sonipat, Hisar), Rajasthan (Bharatpur, Dig, Kaman, Kumher, Nadbai, Nagar, Rupbas, Bari, Dhaulpur), Delhi, and UP. Maximum number of blocks lies in UP including Agra, Khairagarh, Kiraoli, Aligarh, Iglas, Khair, Sikandra Rao, Baghpat, Bijnor, Anupshahr, Bulandshahr, Jalesar, Etmadpur, Khurja, Sikandarabad, Garhmuktesar, Ghaziabad, Hapur, Hathras, Hasanpur, Chhata, Mathura, Mat, Sadabad, Mawana, Meerut, Sardhana, Budhana and Jansath. AQI of these areas were also found to be high (>200) during the pre-lockdown. Consistently high ER\% was observed in nearby regions of Delhi, NCR due to high vehicular pollution, industrial operations and wind circulation pattern. Main reason of high ER\% in the districts of Haryana including Panipat, Gurugram, Faridabad and Hisar during pre-lockdown is industrial emissions. Faridabad is one of the largest industrial cities in Haryana and thus showed high AQI values and high ER\%. Panipat also have many large and small industries such as Thermal Power Plant, National Fertilizer Limited, Oil Refinery and other textile industries. Jindal Steel and power limited is the main reason of the air pollution in Hisar district.

Meteorological parameters were found to be less correlated with the pollutants $\left(r^{2} \leq 0.13\right.$, Table A5 and $A 6$, supplementary material) and thus it may be said that there is very less influence or no influence of meteorology on the pollutants distribution over the study area during the study period. It is expected that, when the wind speed is high (the case of the lockdown period), the pollutants gets dispersed in the atmosphere and air quality gets improved. This logic supports the influence of meteorology on pollutants 
concentration during the year 2020 however, less correlation $\left(r^{2} \leq 0.01\right)$ between pollutants concentration and wind speed showed very less influence. Pattern of the wind direction was also found to be similar for the year 2019 and 2020 (supplementary material Figure S16 and Table A4) which shows less influence of wind direction on pollutants distribution. Temperature and wind direction is almost same in both the years but the $\mathrm{RH}$ and wind speed is little high in 2020. High RH and wind speed must reduce the pollutants concentration and thus $\mathrm{ER} \%$. This logic again supports the influence of meteorology on the pollution level during the year 2020. Nevertheless, low correlation coefficient values $\left(r^{2} \leq 0.12\right)$ indicate less influence of meteorology on pollution level of the year 2020 (Table A5 and A6, supplementary material). This analysis clearly shows that the metrology have least affected the concentration of air pollutants, AQI and ER\% over the region during lockdown.

\section{Conclusion}

The effect of lockdown due to COVID-19 on criteria air pollutants, AQI \& Excess Risk (ER \%) were examined in Northern part of India taking ground based data $(n=47)$ from January to June, 2019 and 2020 and GIS techniques. PM2.5, PM10, NO2, CO, 03 \& SO2 concentration were less in 2020 as compared to the concentration of these pollutants in the year 2019. In pre-lockdown period PM 2.5 concentration was $71.1 \mu \mathrm{g} / \mathrm{m}^{3}$ in study area \& this was greater than CPCB standards but during lockdown period concentration was $38.7 \mu \mathrm{g} / \mathrm{m}^{3}$ and this was less than the CPCB standards $\left(40 \mu \mathrm{g} / \mathrm{m}^{3}\right)$ for a good quality of air. $\mathrm{PM}_{2.5}, \mathrm{PM}_{10}, \mathrm{NO}_{2}, \mathrm{NH}_{3}$ and $\mathrm{CO}$ decreased by $46 \%, 31 \%, 39 \%, 24 \%$ and $34 \%$ in lockdown scenario as compared to the pre-lockdown scenario. $\mathrm{SO}_{2}$ concentration was not declined because no restriction on coal based power plants and crop residue burning in this part of north India, considered as major source of $\mathrm{SO}_{2}$. Ozone $\left(\mathrm{O}_{3}\right)$ concentration was increased in lockdown period may be because of clear sky, sunlight availability and presence of $\mathrm{O}_{3}$ forming nuclei's along with other pollutants resulted in to high rate of photo-reactions and thus high $\mathrm{O}_{3}$.

Decreasing trends of concentrations of pollutants clearly show the effect of lockdown on air quality (AQI). Air quality was degraded in this region since last few years but in 2020 the air quality gets improved due to lockdown measures amid COVID-19. Millions of people die every year in India due to respiratory disease resulted from high air pollution. The ER\% get reduced significantly in the year 2020 which may possibly cut the deaths due to air pollution however, for exact increase in life expectancy future research is required. Anthropogenic activities are the main causes of increasing the air pollutants in this region. The blocks identified under high ER\% may be considered for air quality improvement and management sites. Meteorology have very less or no influence on pollutants concentration over the study area during the study period.

\section{Materials And Methods Study Area}


Study area lies in Northern part of the India between Latitude $29^{\circ} 43^{\prime} 42.091$ to $32^{\circ} 34^{\prime} 27.131^{\prime \prime} \mathrm{N}$ and Longitude $75^{\circ} 51^{\prime} 45.409$ to $78^{\circ} 29^{\prime} 26.983^{\prime \prime} \mathrm{N}$ and constitute part of Indo-Gangetic Plain (IGP) which is among the highly polluted regions in the world. It includes Districts of Haryana, Punjab, Rajasthan, Uttar Pradesh (PU), Delhi and Union territory of Chandigarh (Figure 1).

A total of $\mathbf{4 7}$ ground stations for air pollutants measurement are working in the study area under the maintenance of Central Pollution Control Board (CPCB). Total geographical area is 191032 hectare and largely covered by agriculture and built-up/habitation. The elevation ranges from $140 \mathrm{~m}$ to $673 \mathrm{~m}$. The annual average rainfall is $\otimes 740 \mathrm{~mm}$ with arid to semi-arid type of climate.

It is affected by both type of air pollution sources i.e. natural (dusty wind from Thar desert of arid Rajasthan) and anthropogenic (like biomass and crop stubble burning, Industrial activities, dense population and high transport/vehicular movements). Similar factors are found to be affecting the cities of China [33]. Further the topography and weather conditions also influences the pollution level of the study area. Taking the geographical location, ground data availability and persistent air pollution problem throughout the year (increased pollution in May-June and October-December every year) in to the consideration, the current study area is selected for further analysis.

The current COVID-19 condition has largely affected the anthropogenic activities in the region and thus the changes in the level of air pollutants or AQI is considered to be influenced only by this. The consistencies in natural pollution favouring conditions have also been reported by [20] for these regions. Study area includes 196 blocks distributed in 37 districts of six states and Union Territory having 47 ground stations. A map showing these administrative units is given in Figure S1 (in supplementary material) and list of the administrative units (name of the 196 blocks) are given in Table A2 (supplementary material).

\section{Methodology}

Influence of COVID-19 driven lockdown on air pollution and related Excess Risk (ER \%) is assessed taking three scenarios in to account viz. pre-lockdown, during lockdown and post lockdown. Pollutant concentrations from ground stations were processed for further use in AQI and ER \% estimation and interpolated in GIS environment for assessing spatial variability in pre-defined scenarios. Flowchart of methodology is presented in Figure 2.

\section{Data Source}

To assess the AQI and related health risk (ER \%) of selected study area in predefined scenarios namely prelockdown, during lockdown and post-lockdown, the ground data from CPCB stations $(n=47)$ were downloaded for a period of six months starting from 01 January to 30 June of the year 2019 and 2020 on daily temporal resolution from https://app.cpcbccr.com/ccr/\#/caaqm-dashboard-all/caaqmlanding/caaqm-comparison-data. Ground stations are distributed and located at the various parts of the different states \& territory in northern India (Delhi, Chandigarh, Haryana, Punjab, Uttar Pradesh, and 
Rajasthan). Daily concentration of seven criteria pollutants (PM2.5, PM10, NO2, NH3, CO, 03 \& SO2.) has been collected and processed at individual station level. The CPCB facility provides 24 -hour average concentration of the PM2.5, PM10, NO2, NH3, SO2 and 8-hour average $\mathrm{CO}, 03$ respectively. Stations along with their geographical coordinates and average AQI during study period (January-June, 2020) are listed in the Table A1 (Supplementary material).

\section{Statistics of Criteria Pollutants}

In this study, seven criteria pollutants are assessed including PM2.5, PM10, NO2, NH3, CO, 03 and SO2. Statistical analysis was done for the description of the concentration of all pollutants (for whole time period as well as for three scenarios) which includes the mean, median, mode, minimum, maximum and standard deviation. The statistics for the three scenarios are presented as box plot in the results section. This was further analysed for the effect of COVID-19 driven lockdown on air pollutants.

\section{Air Quality Index (AQI)}

AQI defines the transformation of the weighted value of the parameters of air pollutants into the single, unit less number. Out of all the criteria pollutants viz. PM2.5, PM10, NO2, NH3, CO, 03 and $\mathrm{SO} 2$ a minimum of three pollutants should be available and one should be PM10 or PM2.5 as suggested by CPCB. AQI scale varies from 0 to 500 and divided into six categories viz. Good (0-50), Satisfactory (51-100), Moderate (101-200), Poor (201-300), Very poor (301-400) and Severe (401-500). Two steps are involved into the AQI calculation. In first step, Sub-Index is calculated for each air pollutant by using the following formula [34].

$$
I_{i}=\frac{I_{H I-I_{L O}}}{B_{H I-B_{L O}}} *\left(C_{P}-B_{L O}\right)+I_{L O}
$$

Where;

$I_{i}=$ Sub Index

$I_{H I}=A Q I$ Value Corresponding of the $B_{H I}$

$\mathrm{B}_{\mathrm{HI}}=$ Greater Breakdown Concentration

$\mathrm{I}_{\mathrm{LO}}=\mathrm{AQI}$ Value Corresponding of the $\mathrm{B}_{\mathrm{LO}}$

$\mathrm{B}_{\mathrm{LO}}=$ Smaller Breakdown Concentration

$C_{p}=$ Concentration of Pollutant 
In the second step AQI is calculated from the maximum concentration of the sub index of the all air pollutant, as shown in equation two

$A Q I=\operatorname{Max}\left(I_{i}\right)$

Where; $\mathrm{i}=1,2, \ldots, \mathrm{n} ; \mathrm{n}$ denotes pollutants

Concentration ranges for individual pollutants those limits the categories of AQI are listed in Table 1. These limits are called break points and identified by CPCB for AQI estimation. Further, the average values of $A Q I$ in three scenarios were analysed both statistically as well as in spatial domain for understanding the effect of COVID-19 driven lockdown. Inverse Distance weighting (IDW) method of spatial interpolation is used for understanding variations in spatial domain as suggested by [35]. Maps of the concentration of the air pollutants are also prepared and presented in supplementary materials (Figure S2 to S8).

\section{Health risk Calculations}

Health risk from the air pollutant is measured in term of exposure of the human being from the concentration of the each pollutant. Pollutants concentration is changed with time and location so health risk of the area is also variable. For the health risk assessment, ER\% was considered. The ER\% was estimated based on Relative Risk (RR) of each pollutant. RR of the each pollutant are estimated by following the equation 3 (Sharma et al., 2020).

$R R_{i}=\exp \left[\beta_{i}\left(C_{i}-C_{i, 0}\right)\right], C_{i}>C_{i, 0}$

Where RRi is the Relative Risk of pollutant $i, \beta_{\mathrm{i}}$ is exposure response coefficient of additional health risk (Such as mortality) caused by per unit of pollutant $i$, when it exceeds a thresholds concentration. $C_{i}$ is the concentration of the pollutant $i$ and $\mathrm{C}_{\mathrm{i}, 0}$ is the threshold concentration of pollutant (when threshold concentration of pollutant is less than the pollutant concentration then relative risk is greater than 0 ). $\beta_{\mathrm{i}}$ and threshold value taken for the present study are presented in Table 1. ER $\% \%$ and total ER\% of the pollutant is estimated by using equation 4 and 5 [5].

$E R_{i}=R R_{i}-1$

$$
E R_{\text {total }}=\sum_{i=1}^{n} E R_{i}
$$

\section{References}


1. World Health Organization (WHO). http://www.emro.who.int/health-topics/corona-virus/about-covid19.html [accessed 20 November 2020] (2020).

2. Lal, P., Kumar, A., Kumar, S., Kumari, S., Saikia, P., Dayanandan, A., Adhikari, D. \& Khan, M. L. The dark cloud with a silver lining: assessing the impact of the SARS COVID-19 pandemic on the global environment. Total Environ. 732, 139297. https://doi.org/10.1016/j.scitotenv.2020.139297 (2020).

3. Muhammad, S., Long, X. \& Salman, M. Science of the Total Environment COVID-19 pandemic and environmental pollution. Total Environ. 728, 138820. https://doi.org/10.1016/j.scitotenv.2020.138820 (2020).

4. Mahato, S., Pal, S. \& Ghosh, K. G. Effect of lockdown amid COVID-19 pandemic on airquality of the megacity Delhi, India. Total Environ. 730, 139086. https://doi.org10.1016/j.scitotenv.2020.139086 (2020).

5. Sharma, S., Zhang, M., Gao, J., Zhang, H. \& Harsha, S. Effect of restricted emissions during COVID-19 on air quality in India. Total Environ. 728, 138878. https://doi.org/10.1016/j.scitotenv.2020.138878 (2020).

6. Srivastava, S., Kumar, A., Bauddh, K., Sagar, A. \& Sanjeev, G. 21 - Day Lockdown in India Dramatically Reduced Air Pollution Indices in Lucknow and New Delhi , India. Environ. Contam. Toxicol. 105, 9-17. https://doi.org/10.1007/s00128-020-02895-w (2020).

7. Tobías, A., Carnerero, C., Reche, C., Massagué, J., Via, M., Minguillón, M. C., Alastuey, A. \& Querol, X. Changes in air quality during the lockdown in Barcelona (Spain)one month into the SARS-CoV-2 epidemic. Total Environ. 726, 138540. https://doi.org/10.1016/j.scitotenv.2020.138540 (2020).

8. Bao, R. \& Zhang, A. Science of the Total Environment Does lockdown reduce air pollution? Evidence from 44 cities in northern China. Total Environ. 731, 139052. https://doi.org/10.1016/j.scitotenv.2020.139052 (2020).

9. Filonchyk, M., Hurynovich, V., Yan, H., Gusev, A. \& Shpilevskaya, N. Impact Assessment of COVID-19 on Variations of SO2, NO2, CO and AOD over East China. Air Qual. Res.20 (2020).

10. Ma, X., Wang, D., Xu, W., Wu, G., Gao, G. F. D. \& Tan, W. A Novel Coronavirus from Patients with Pneumonia in China, 2019. New England Journal of Medicine. 1-7. https://doi.org/10.1056/NEJMoa2001017 (2020).

11. World Health Organization (WHO). https://covid19.who.int/[accessed 12 August 2020] (2020).

12. Sharma, A. Invest India, 2020. What constitutes Essential Services during Lockdown?, https://www.investindia.gov.in/team-india-blogs/what-constitutes-essential-services-during-lockdown (accessed on 7 August 2020) (2020).

13. Guo, H., Harsha, S., Kumar, S., Hu, J., Ying, Q., Gao, A. \& Zhang, H. Source apportionment of PM 2 . 5 in North India using source-oriented air quality models*. Pollut. 231, 426-436. https://doi.org/10.1016/j.envpol.2017.08.016 (2017).

14. Tiwari, S., Hopke, P. K., Pipal, A. S., Srivastava, A. K., Bisht, D. S., Tiwari, S., Singh, A. K., Soni, V. K. \& Attri, S. D. Intra-urban variability of particulate matter (PM2.5 and PM10) and its relationship with optical properties of aerosols over Delhi, India. Res. 166, 223-232 (2015). 
15. Pratap, V., Kumar, A., Tiwari, S., Kumar, P., Tripathi, A. K. \& Singh, A. K. Chemical characteristics of particulate matters and their emission sources over Varanasi during winter season. Journal of Atm. Che. https://doi.org/10.1007/s10874-020-09405-6 (2020).

16. Dantas, G., Siciliano, B., França, B. B., da Silva, C. M. \& Arbilla, G. The impact of COVID-19 partial lockdown on the air quality of the city of Rio de Janeiro, Brazil. Total Environ. 729, 139085. https://doi.org/10.1016/j.scitotenv.2020.139085 (2020).

17. Nakada, L. Y. K. \& Urban, R. C. COVID-19 pandemic: impacts on the air quality during the partial lockdown in São Paulo state, Brazil. Total Environ. 730, 139087.https://doi.org/10.1016/j.scitotenv.2020.139087 (2020).

18. Otmani, A., Benchrif, A., Tahri, M., Bounakhla, M., Chakir, E. M., El Bouch, M. \& Krombi, M. Impact of Covid-19 lockdown on PM10, SO2 and NO2 concentrations in Salé City (Morocco). Total Environ. 735, 139541. https://doi.org/10.1016/j.scitotenv.2020.139541 (2020).

19. Filonchyk, M. \& Hurynovich, V. Validation of MODIS Aerosol Products with AERONET Measurements of Different Land Cover Types in Areas over Eastern Europe and China. Geovisualization Spat Anal. 4. https://doi.org/10.1007/s41651-020-00052-9 (2020).

20. Bhawre, P. Study of air quality index over indian region during lockdown research article study of air quality index over indian region during lockdown period, COVID19. journal of current resarch. https://doi.org/10.24941/ijcr.38710.06.2020 (2020).

21. Ranjan, A. K., Patra, A. K. \& Gorai, A. K. Effect of lockdown due to SARS COVID-19 on aerosol optical depth (AOD) over urban and mining regions in India. Total Environ. 745: 141024. https://dx.doi.org/10.1016\%2Fj.scitotenv.2020.141024 (2020).

22. Wang, P., Chen, K., Zhu, S., Wang, P. \& Zhang, H. Severe air pollution events not avoided by reduced anthropogenic activities during COVID-19 outbreak. Conserv. Recycl. 158, 104814 (2020).

23. Itten, N. \& Selici, A. T. Investigating the impacts of some meteorological parameters on air pollution in Balikesir, Turkey. Monit. Assess. 267-277. https://doi.org/10.1007/s10661-007-9865-1 (2008).

24. Jayamurugan, R., Kumaravel, B., Palanivelraja, S. \& Chockalingam, M. P. Influence of Temperature, Relative Humidity and Seasonal Variability on Ambient Air Quality in a Coastal Urban Area. J. Atmos. Sci. 2013, 1-7. https://doi.org/10.1155/2013/264046 (2013).

25. He, J., Gong, S., Yu, Y., Yu, L., Wu, L., Mao, H., Song, C., Zhao, S., Liu, H., Li, X. \& Li, R. Air pollution characteristics and their relation to meteorological conditions during 2014 e 2015 in major Chinese cities * 1-13.https://doi.org/10.1016/j.envpol.2017.01.050 (2017).

26. Banerjee, T., Singh, S. B. \& Srivastava, R. K. Development and performance evaluation of statistical models correlating air pollutants and meteorological variables at Pantnagar, India. Res. 99, 505-517. https://doi.org/10.1016/j.atmosres.2010.12.003 (2011).

27. Navinya, C., Patidar, G. \& Phuleria, H. C. Examining effects of the COVID-19 national lockdown on ambient air quality across urban India. Aerosol and Air Quality Research, 20(2020).

28. Dhaka, S. K., Chetna, Kumar, V., Panwar, V., Dimri, A. P., Singh, N., Patra, P. K., Matsumi, Y., Takigawa, M., Nakayama, T., Yamaji, K., Kajino, M., Misra, P. \& Hayashid, S. PM2.5 diminution and haze events over 
Delhi during the COVID-19 lockdown period: an interplay between the baseline pollution and meteorology. Rep. 10, 1-8. https://doi.org/10.1038/s41598-020-70179-8 (2020).

29. Mor, S., Kumar, S., Singh, T., Dogra, S., Pandey, V. \& Ravindra, K. Impact of COVID-19 lockdown on air quality in Chandigarh, India: Understanding the emission sources during controlled anthropogenic activities. 263, 127978. https://doi.org/10.1016/j.chemosphere.2020.127978 (2021).

30. Shehzad, K., Sarfraz, M., Ghulam, S. \& Shah, M. The impact of COVID-19 as a necessary evil on air pollution in India. Pollut. 266, 115080. https://doi.org/10.1016/j.envpol.2020.115080 (2020).

31. Wai, T., Wai, W., Tam, S., Tak, I., Yu, S., Kai, A., Lau, H., Wing, S. \& Wong, A. H. S. Developing a riskbased air quality health index. Environ. 76, 52-58. https://doi.org/10.1016/j.atmosenv.2012.06.071(2013).

32. Data Analysis. https://science.thewire.in/environment/lockdown-air-pollution-north-india-pm25-pm10nox-ozone/[accessed on 2- November 2020] (2020).

33. Huang, Y., Yan, Q., Zhang, C. Spatial - Temporal Distribution Characteristics of PM2 . 5 in China in 2016 Spatial - Temporal Distribution Characteristics of PM 2 . 5 in China in 2016. Geovisualization Spat Anal, 2(2), 12. https://doi.org/10.1007/s41651-018-0019-5 (2018).

34. Gorai, A. K., Goyal P. A Review on Air Quality Indexing System. Asian Journal of Atmos. Environ. 9(2), 101-113. https://doi.org/10.5572/ajae.2015.9.2.101(2016).

35. Kumar A, Gupta I, Brandt J, Kumar R, Dikshit A K, Patil R S. Air quality mapping using GIS and economic evaluation of health impact for Mumbai city, India. Journal of the Air \& Waste Management Association, 66(5), 470-481(2016).

\section{Declarations}

\section{Acknowledgements}

CPCB is acknowledged for providing ground based air pollution data.

\section{Author contributions}

D.S. performed data analysis, directed and supervised the whole project and wrote manuscript. M.D. participated with a major role in constructing AQI and ER models, data analysis and draft manuscript formatting. C.N. supported in data modification and preparation the manuscript.

\section{Additional Information}

Authors declare no competing interests.

\section{Tables}

Table 1: $\beta_{i} \&$ threshold value for each criteria pollutant required for Relative Risk (RR) estimation 


\begin{tabular}{|llllll|}
\hline S.no. & $\mathrm{PM} 2.5 \mu \mathrm{g} / \mathrm{m}^{3}$ & $\mathrm{PM} 10 \mu \mathrm{g} / \mathrm{m}^{3}$ & $\mathrm{NO2} \mu \mathrm{g} / \mathrm{m}^{3}$ & $\mathrm{CO} \mathrm{mg} / \mathrm{m}^{3}$ & $\mathrm{sO2} \mu \mathrm{g} / \mathrm{m}^{3}$ \\
& (24-hour) & (24-hour) & (24-hour) & (24-hour) & (24-hour) \\
\hline B-Value & $0.038 \%$ & $0.032 \%$ & $0.13 \%$ & $3.7 \%$ & $0.081 \%$ \\
\hline Threshold value & 35 & 50 & 40 & 2 & 50 \\
\hline
\end{tabular}

Table 2: Statistical values of parameters (in $\mu \mathrm{g} / \mathrm{m}^{3}$ except for $\mathrm{CO}$ which is measured in $\mathrm{mg} / \mathrm{m}^{3}$ ) in three scenario (Pre, during and Post Lockdown) 


\begin{tabular}{|c|c|c|c|c|c|c|c|}
\hline $\begin{array}{l}\text { Lockdown } \\
\text { scenario }\end{array}$ & Parameters & $\begin{array}{l}\text { Total } \\
\text { Observations }\end{array}$ & Mean & $\begin{array}{l}\text { Standard } \\
\text { Deviation }\end{array}$ & Minimum & Median & Maximum \\
\hline \multirow[t]{7}{*}{ Pre } & PM2.5 & 3688 & 71.12 & 44.95 & 3.42 & 59.53 & 475.22 \\
\hline & PM10 & 3474 & 139.29 & 72.77 & 16.19 & 121.72 & 591.96 \\
\hline & NO2 & 3571 & 28.17 & 20.88 & 1.16 & 23.64 & 247.49 \\
\hline & $\mathrm{NH} 3$ & 3042 & 33.31 & 23.97 & 0.57 & 28.20 & 310.40 \\
\hline & $\mathrm{CO}$ & 3633 & 1.00 & 0.65 & 0.01 & 0.82 & 5.23 \\
\hline & 03 & 3548 & 28.73 & 20.08 & 1.18 & 22.72 & 148.86 \\
\hline & SO2 & 3404 & 13.75 & 10.85 & 0.72 & 10.87 & 173.76 \\
\hline \multirow[t]{7}{*}{ During } & PM2.5 & 3242 & 38.67 & 20.14 & 3.93 & 34.64 & 156.26 \\
\hline & PM10 & 2979 & 96.06 & 54.86 & 10.68 & 82.58 & 348.35 \\
\hline & NO2 & 3027 & 17.29 & 13.49 & 0.28 & 14.46 & 151.16 \\
\hline & $\mathrm{NH} 3$ & 2545 & 25.45 & 17.88 & 2.49 & 22.38 & 288.12 \\
\hline & $\mathrm{CO}$ & 3167 & 0.66 & 0.46 & 0.01 & 0.53 & 5.38 \\
\hline & 03 & 3071 & 38.89 & 22.69 & 1.96 & 33.73 & 134.81 \\
\hline & SO2 & 2944 & 13.69 & 11.56 & 1.24 & 10.72 & 161.16 \\
\hline \multirow[t]{7}{*}{ Post } & PM2.5 & 1364 & 40.44 & 16.78 & 5.32 & 38.35 & 124.80 \\
\hline & PM10 & 1242 & 104.94 & 56.58 & 20.74 & 90.66 & 456.20 \\
\hline & NO2 & 1316 & 18.47 & 12.15 & 0.05 & 16.42 & 99.79 \\
\hline & $\mathrm{NH} 3$ & 1107 & 29.05 & 22.31 & 0.22 & 25.29 & 171.48 \\
\hline & $\mathrm{CO}$ & 1319 & 0.69 & 0.50 & 0.01 & 0.60 & 5.25 \\
\hline & 03 & 1310 & 38.55 & 22.09 & 1.20 & 33.69 & 125.83 \\
\hline & $\mathrm{SO} 2$ & 1243 & 12.7 & 8.9 & 0.52 & 8.93 & 85.36 \\
\hline
\end{tabular}

Table 3: Statistical analysis of Air Quality Index (AQI) in different scenarios of lockdown 


\begin{tabular}{|lllllll|}
\hline AQI & N total & Mean & SD & Minimum & Median & Maximum \\
\hline Pre-Lockdown & 3731 & 154 & 87.58 & 20.4 & 121.03 & 602.45 \\
\hline During Lockdown & 3254 & 94 & 46.49 & 16.98 & 86.085 & 327.89 \\
\hline Post Lockdown & 1415 & 100 & 47.07 & 24 & 91.13 & 432.75 \\
\hline
\end{tabular}

\section{Figures}

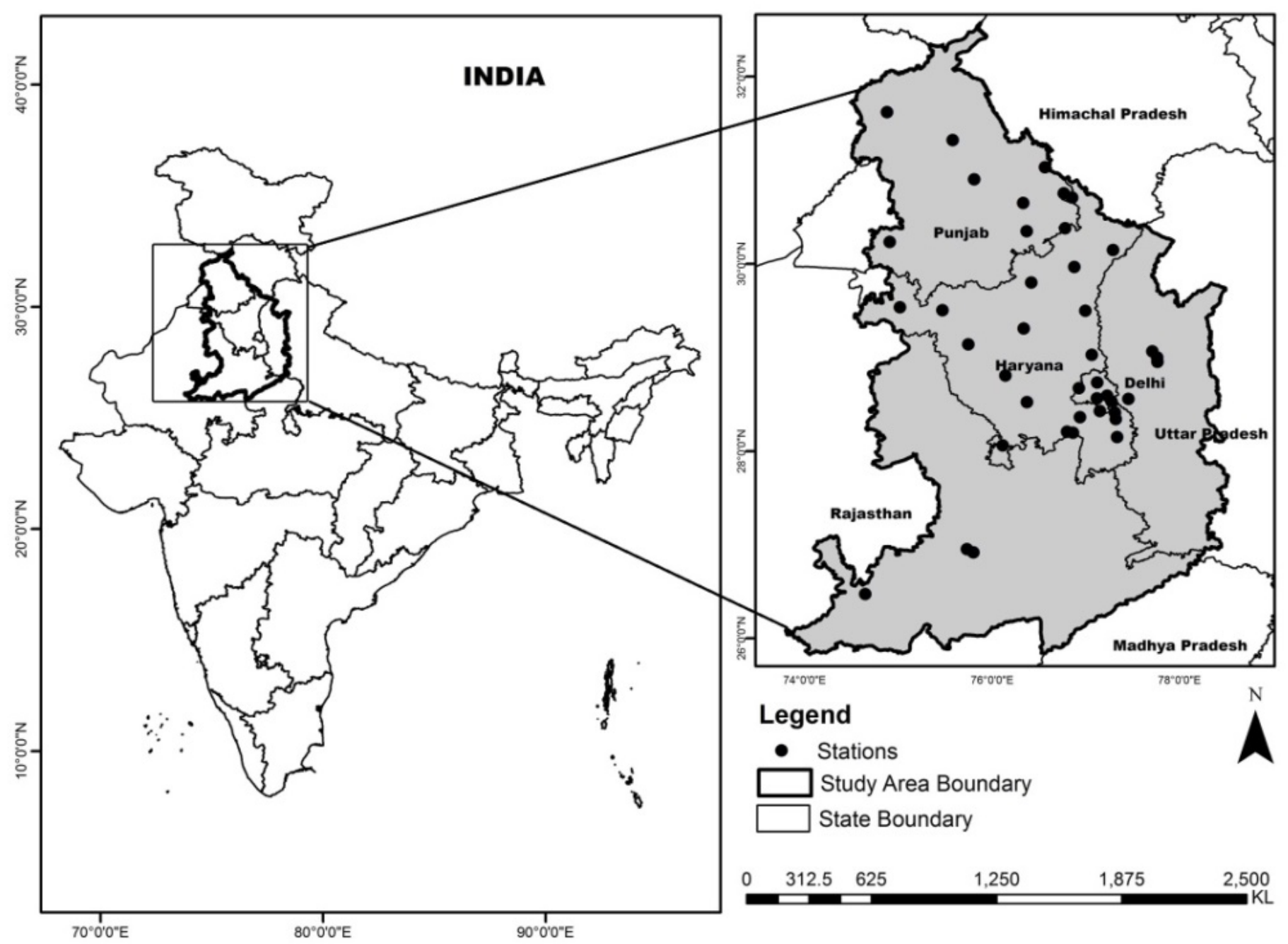

Figure 1

Study area map showing distribution of ground station as black dot. Note: The designations employed and the presentation of the material on this map do not imply the expression of any opinion whatsoever on the part of Research Square concerning the legal status of any country, territory, city or area or of its authorities, or concerning the delimitation of its frontiers or boundaries. This map has been provided by the authors. 


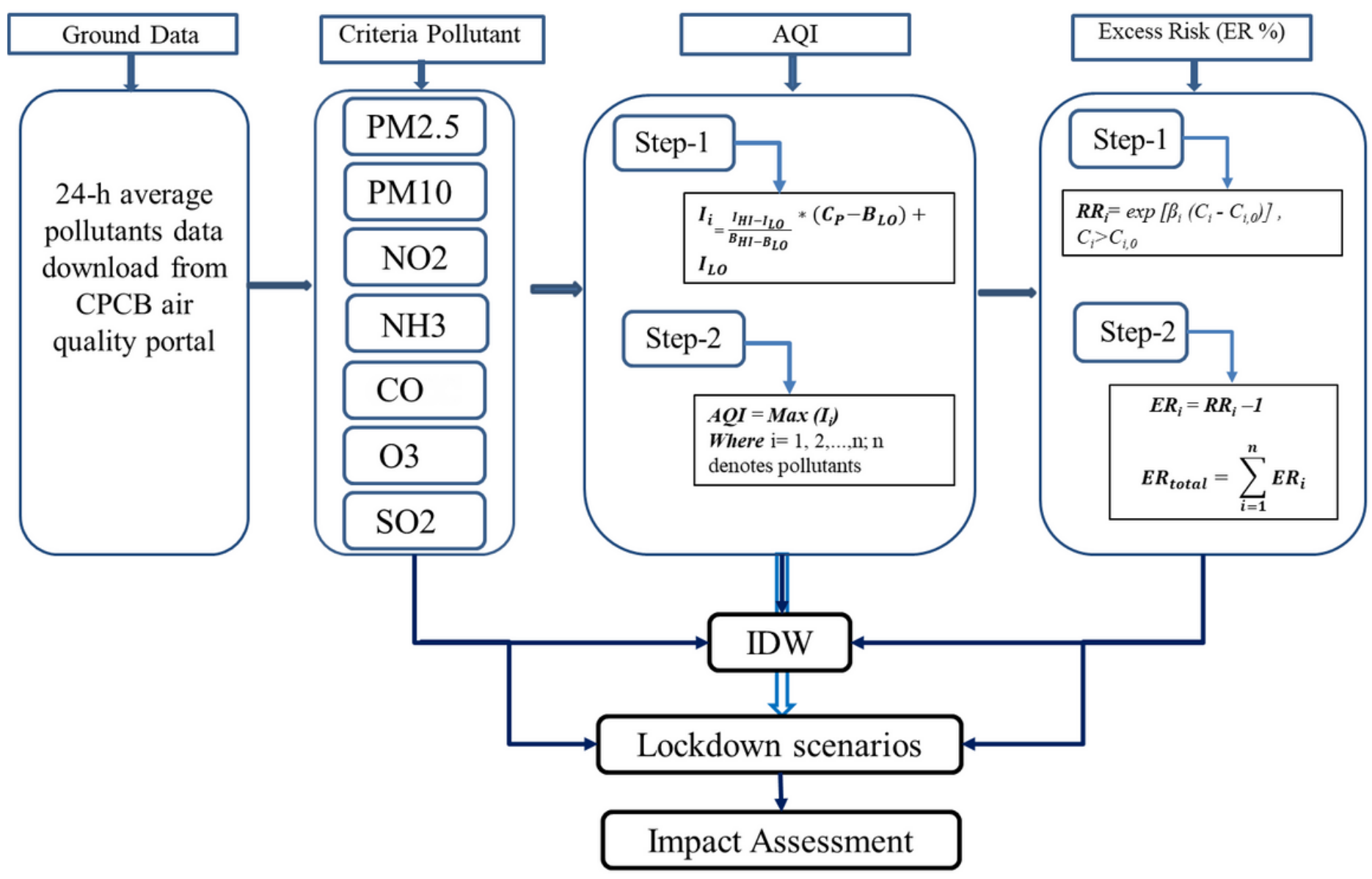

Figure 2

Flowchart of method applied for the current study 

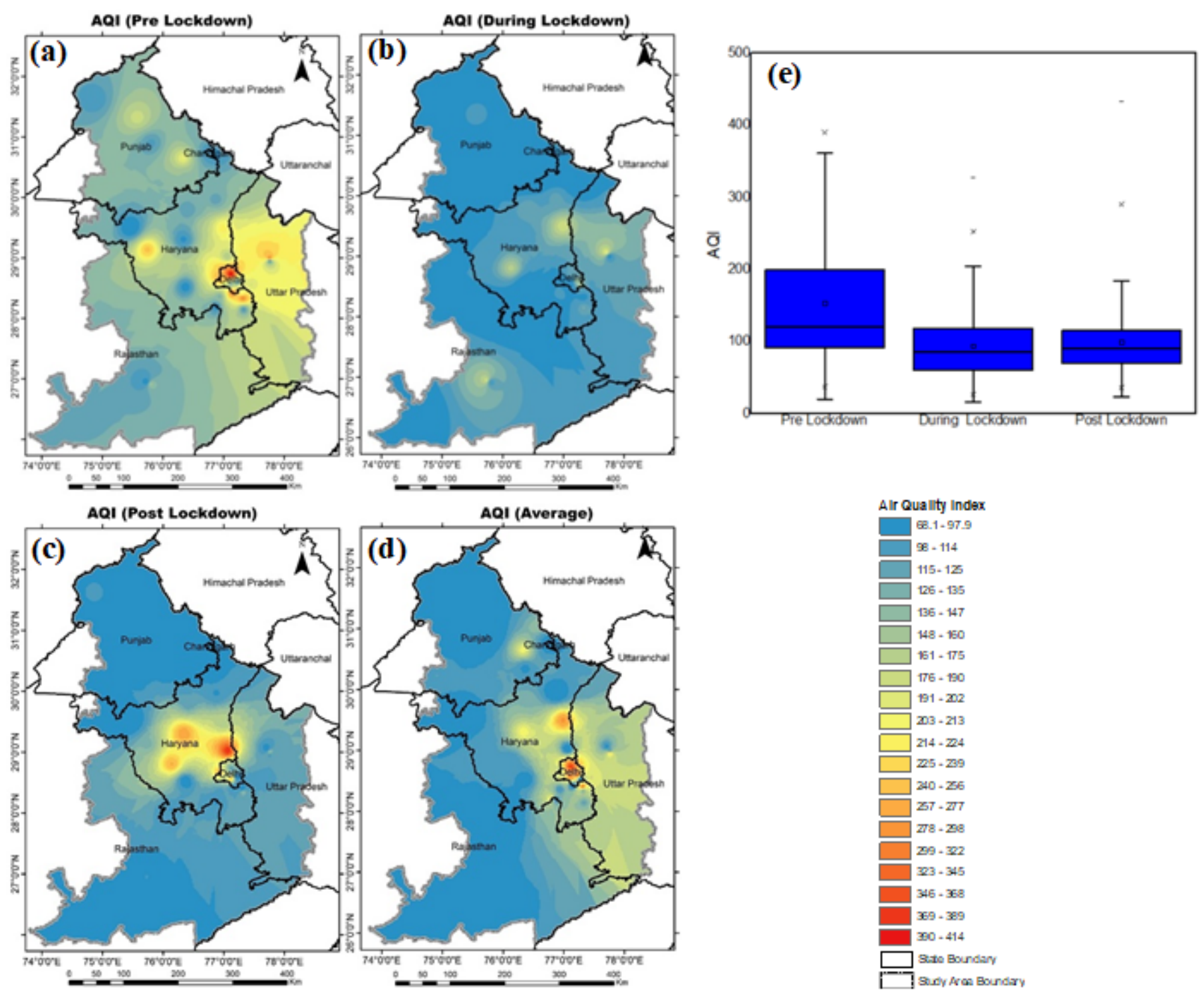

Figure 3

AQI of the study area in four time frame i.e. Pre-Lockdown (a), During Lockdown (b), Post-Lockdown (c) \& Average of Six Month (d) and box plot for AQI statistics (e). High values of AQI is observed in pre-lockdown period while low in during and post lockdown period. High average AQI values in National Capital Region (NCR) may be observed in average AQI (3d). Note: The designations employed and the presentation of the material on this map do not imply the expression of any opinion whatsoever on the part of Research Square concerning the legal status of any country, territory, city or area or of its authorities, or concerning the delimitation of its frontiers or boundaries. This map has been provided by the authors. 

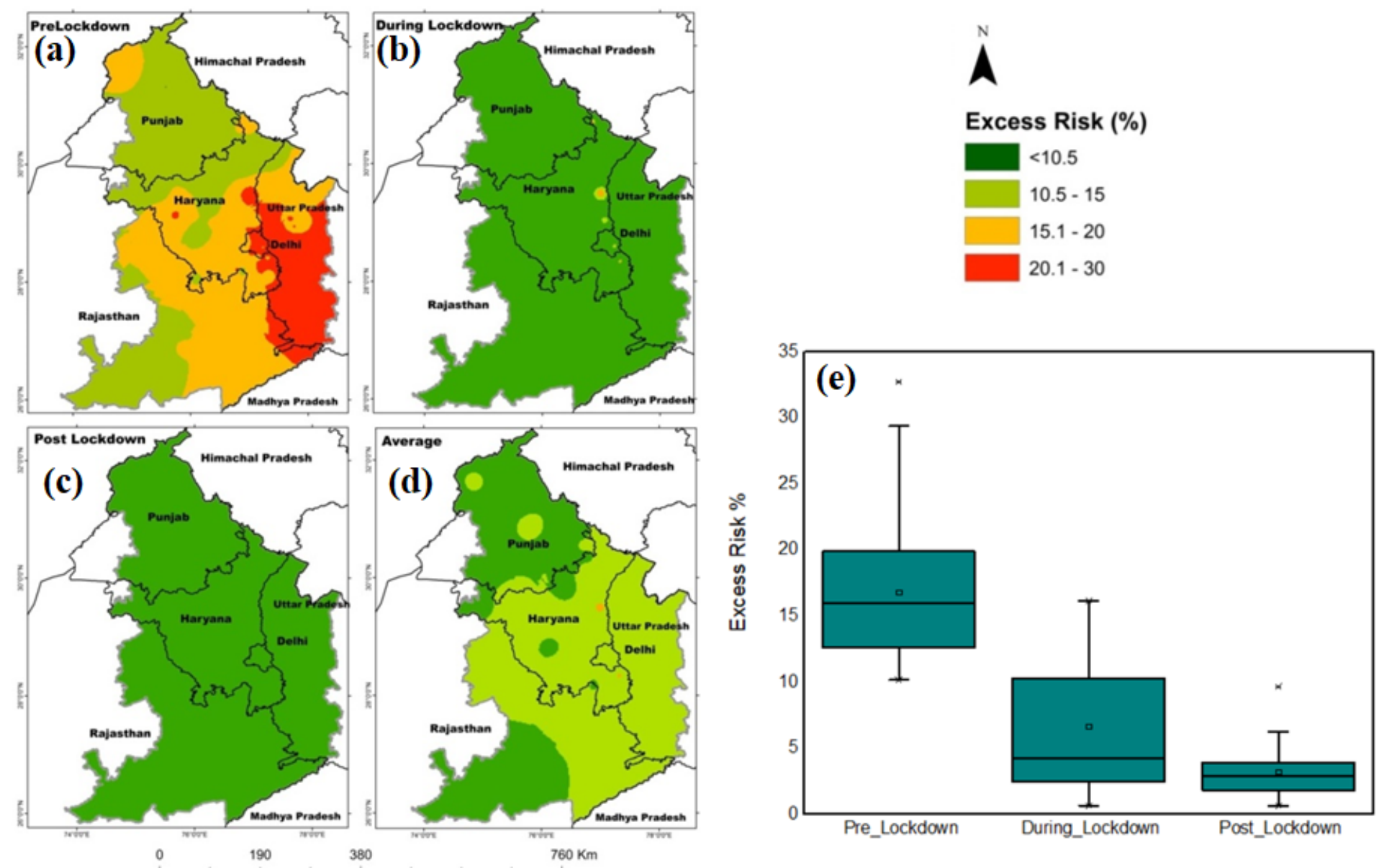

Figure 4

Excess Risk (ER \%) at different scenarios of COVID-19 i.e. Pre-Lockdown (a), During Lockdown (b), PostLockdown (c) \& Average of Six Month (d) and box plot for ER\% statistics (e). High values of ER\% is observed in pre-lockdown period while low in during and post lockdown period. High average ER\% in National Capital Region (NCR) and over Haryana may be observed in average ER\% (3d). Note: The designations employed and the presentation of the material on this map do not imply the expression of any opinion whatsoever on the part of Research Square concerning the legal status of any country, territory, city or area or of its authorities, or concerning the delimitation of its frontiers or boundaries. This map has been provided by the authors.

\section{Supplementary Files}

This is a list of supplementary files associated with this preprint. Click to download.

- SupplimentaryMaterialsnew1.pdf 